\title{
Kejadian bayi berat lahir rendah berhubungan dengan ibu hamil bersuamikan perokok aktif
}

\author{
Gustian Satria Pratama ${ }^{1}$ Raditya Wratsangka ${ }^{2}$
}

\begin{abstract}
ABSTRAK
\section{LATAR BELAKANG}

Bayi Berat Lahir Rendah (BBLR) merupakan salah satu penyebab tingginya angka kematian perinatal dan neonatal. Prevalensi BBLR di seluruh dunia mencapai $15 \%$ dari seluruh kelahiran, dan $>97 \%$ di antaranya terjadi di negara berkembang. Perilaku negatif selama kehamilan seperti paparan asap rokok dapat menurunkan perfusi plasenta sehingga menurunkan penerimaan $\mathrm{O}_{2}$ bagi janin, yang akan meningkatkan risiko kelahiran BBLR. Paparan asap pembakaran tembakau juga menurunkan $20 \%$ kadar asam folat di dalam tubuh yang menyebabkan terganggunya pertumbuhan janin di dalam rahim. Penelitian ini bertujuan untuk mengetahui hubungan antara paparan asap rokok pada ibu hamil yang bersuamikan perokok aktif dan kejadian BBLR.
\end{abstract}

\section{METODE}

Penelitian dengan disain observasional analitik dan pendekatan potong lintang untuk mengetahui hubungan antara ibu hamil bersuamikan perokok aktif (variabel bebas) dan kejadian BBLR (variabel tergantung). Populasi terjangkau adalah ibu hamil yang melahirkan di RSUD Karawang pada bulan Januari sampai Agustus 2017, dan pengambilan sampel dilakukan secara acak sederhana. Data penelitian ini merupakan data primer dan sekunder, yaitu berupa data kuesioner yang didapat dari ibu hamil bersuamikan perokok aktif dan rekam medik untuk data bayi BBLR. Pengolahan dan analisis data menggunakan Statistical Package for Social Sciences (SPSS), dan uji chi square dengan derajat kepercayaan (CI) $95 \%$ dan batas kemaknaan 0.05 .

\section{HASIL}

Subyek penelitian berjumlah 132 orang, dan terdapat 96 bayi (73\%) dengan kasus BBLR. Terdapat hubungan bermakna antara ibu hamil bersuamikan perokok aktif dan kejadian BBLR $(p=0.000(p \leq 0.05))$.

\section{KESIMPULAN}

Terdapat hubungan antara ibu hamil bersuamikan perokok aktif dan kejadian BBLR

Kata kunci : Bayi Berat Lahir Rendah (BBLR), perokok
${ }^{1}$ Program Studi Kedokteran,

Fakultas Kedokteran, Universitas Trisakti

${ }^{2}$ Departemen Obstetri dan Ginekologi, Fakultas Kedokteran, Universitas Trisakti

\section{Korespondensi:}

Raditya Wratsangka

Departemen Obstetri dan

Ginekologi,

Fakultas Kedokteran Universitas Trisakti, Jalan Kyai Tapa No. 260, Grogol, Jakarta Barat.

Email: raditya@trisakti.ac.id

J Biomedika Kesehat 2018;1(2):133139 DOI: 10.18051/JBiomedKes.2018. v1.133-139

pISSN: 2621-539X / eISSN: 2621-5470

Artikel akses terbuka (open access) ini didistribusikan di bawah lisensi Creative Commons Attribution 4.0 International (CC-BY 4.0) 


\section{ABSTRACT}

\section{The incidence of low birth weight associated with pregnant women having husband as active smokers}

\section{BACKGROUND}

Low Birth Weight (LBW) baby may cause high number of perinatal and neonatal mortality. The prevalence of LBW worldwide is estimated at $15 \%$ of all births, and more than $97 \%$ occurs in developing countries. Negative behaviour during pregnancy such as cigarette smoke can decrease placental perfusion hence decreasing $\mathrm{O}_{2}$ acceptance for the fetus which increases the risk of delivering LBW babies. Exposure to tobacco-burning also lowers $20 \%$ of folic acid level that cause fetal growth restriction inside the womb. This study aims to determine the relation between exposure to cigarette smoke to the pregnant women and the occurrence of LBW.

\section{METHODS}

This research uses observational analytic method with research design using cross sectional approach. The population is all pregnant women who deliver babies in Karawang Regional General Hospital from January to August 2017. Samples are taken using simple random sampling. The material is obtained from primary and secondary data. Primary data consisting of data on pregnant women with active smoker husband through questionnaire. While secondary data consists of data about LBW known through medical record. The data analysis used chi square test to measure the relationship between the two variables and using degree of trust (CI) $95 \%$ and significance level 0.05 .

\section{RESULT}

This study involved of 132 subjects who have active smokers of smokers, such as with cases of LBW as many as 96 babies $(73 \%)$. The results of this study indicate a significant relationship between the active smoker husband to the occurrence of LBW with significance value $p=0.000(p \leq 0.005)$.

\section{CONCLUSION}

This study revealed a relationship of pregnant women whose husbands are active smokers with the prevalence of low birth weight baby.

Keywords : Low Birth Weight (LBW), smokers

\section{PENDAHULUAN}

Bayi Berat Lahir Rendah (BBLR) merupakan bayi dengan berat lahir kurang dari 2500 gram, yang ditimbang dalam waktu 1 jam setelah lahir. Prevalensi BBLR di seluruh dunia diperkirakan $15 \%$ dari seluruh kelahiran, 97\% di antaranya terjadi di negara sedang berkembang atau sosial ekonomi rendah. ${ }^{(1)}$ World Health Organization (WHO) melaporkan di Indonesia terdapat 9\% kasus bayi dengan berat badan lahir rendah. ${ }^{(2)}$ Bayi Berat Lahir Rendah (BBLR) merupakan salah satu penyebab tingginya angka kematian perinatal dan neonatal. ${ }^{(3)}$ Perilaku negatif selama kehamilan seperti paparan asap rokok dapat meningkatkan risiko kelahiran BBLR. $(2,4)$ Tiga komponen toksik yang utama pada rokok adalah karbonmonoksida (CO), nikotin $\left(\mathrm{C}_{10} \mathrm{H}_{14} \mathrm{~N}_{2}\right)$ dan tar. Karbonmonoksida yang terabsorbsi ke dalam tubuh ibu secara langsung akan mengikat hemoglobin $(\mathrm{Hb})$ yang mengakibatkan kapasitas $\mathrm{O}_{2}$ di dalam darah akan berkurang sehingga berbahaya bagi ibu karena janin menerima $\mathrm{O}_{2}$ lebih sedikit. Nikotin merupakan vasokonstriktor yang dapat menurunkan perfusi plasenta dan menurunkan penerimaan $\mathrm{O}_{2}$ bagi janin. Paparan asap pembakaran tembakau juga menurunkan $20 \%$ kadar asam folat di dalam tubuh yang menyebabkan terganggunya pertumbuhan janin di dalam rahim. ${ }^{(2,5,6)}$

Prevalensi perokok aktif laki-laki di Indonesia adalah sebesar $66 \%$ dan perempuan sebesar $31.8 \%$, dengan rerata konsumsi rokok sebanyak 10 batang per hari sebesar $51.7 \%$ dan 11-20 batang per hari sebesar $42.6 \%$. Perokok pasif adalah seseorang yang bukan perokok namun tinggal serumah dengan perokok aktif yang merokok di dalam rumah. Penelitian terdahulu menunjukkan paparan asap rokok pada ibu hamil dapat meningkatkan risiko kelahiran BBLR (OR=1.29; 95\% CI: 1.061.57)..$^{(2,6-8)}$

Penelitian ini bertujuan untuk menilai hubungan antara ibu hamil yang bersuamikan perokok aktif dengan kejadian BBLR. 


\section{METODE}

\section{Rancangan penelitian}

Penelitian ini merupakan studi observasional analitik dengan pendekatan potong lintang (cross sectional) untuk menilai hubungan ibu hamil yang bersuamikan perokok aktif dan kejadian BBLR.

\section{Populasi dan subyek penelitian}

Populasi penelitian ini adalah ibu hamil yang melahirkan di Rumah Sakit Umum Daerah (RSUD) Karawang periode Januari sampai Agustus 2017, dengan menggunakan data primer dan sekunder. Data sekunder berupa data ibu hamil dan bayi yang dilahirkan diambil dari data rekam medik RS, sedangkan data primer mengenai kebiasaan merokok suami didapat melalui pengisian kuesioner. Kriteria inklusi subyek penelitian antara lain adalah usia ibu hamil antara 15-49 tahun, usia kehamilan cukup bulan (aterm), sedangkan kriteria eksklusi subyek antara lain adalah ibu hamil penderita hipertensi, diabetes mellitus dan mempunyai kebiasaan merokok. Besar sampel yang dilibatkan dalam penelitian ini dihitung dengan menggunakan rumus :

$$
\eta о=\frac{Z \alpha^{2} x P(1-P)}{d^{2}}
$$

$$
\begin{aligned}
\eta o= & \text { Jumlah sampel infinit } \\
\mathrm{Z} \alpha= & \text { Tingkat kemaknaan } \\
& \text { dikehendaki adalah } 95 \%, \\
& \text { maka } 1.96 \\
\mathrm{P} & =\text { Proporsi prevalensi kejadian } \\
\mathrm{d} & = \\
& \text { Prevalensi }>10 \%, \text { nilai yang } \\
& \text { sudah ditentukan } 0.05
\end{aligned}
$$

Berdasarkan Riset Kesehatan Dasar tahun 2013 menyatakan bahwa prevalensi BBLR di Indonesia adalah $10.2 \%$ dan perhitungan kemungkinan putus studi (drop out) sebesar $15 \%$, maka jumlah sampel penelitian yang dibutuhkan adalah sebanyak 132 subyek.

Berdasarkan data kegiatan kamar bersalin RSUD Karawang jumlah ibu hamil dan melahirkan pada periode bulan Januari sampai Agustus tahun 2017 adalah sebanyak 544 orang. Pengambilan sampel dilakukan secara acak sederhana (simple random sampling) dari kelompok subyek yang memenuhi kriteria inklusi dan eksklusi. Seluruh subyek yang dilibatkan diberikan penjelasan dan dimintakan persetujuannya yang dinyatakan dalam bentuk informed consent. Pengolahan data menggunakan piranti lunak Statistical Package for Social Science (SPSS) v.25 for Windows, sedangkan analisis data menggunakan uji chi square dengan derajat kepercayaan (confidence interval) $95 \%$ dan batas kemaknaan 0.05 untuk menilai hubungan antara ibu hamil yang bersuamikan perokok aktif dengan kejadian BBLR.

Penelitian ini telah lolos proses kaji etik dan disetujui untuk dilaksanakan oleh Komisi Etik Riset Fakultas Kedokteran Universitas Trisakti melalui Surat Keputusan Nomor 94/KER-FK/VII/2017.

\section{HASIL}

Penelitian ini dilaksanakan pada bulan September sampai Desember 2017 dengan melibatkan sebanyak $132 \mathrm{ibu}$ hamil dan melahirkan di RSUD Karawang selama bulan Januari sampai dengan Agustus 2017 sebagai subyek penelitian.

Tabel 1. Distribusi subyek berdasarkan karakteristik demografik $(n=132)$

\begin{tabular}{lrl}
\hline \multicolumn{1}{c}{ Karakteristik Demografik } & n (\%) \\
\hline Umur ibu & $5(3.7)$ \\
$<20$ tahun & $100(75.8)$ \\
$20-35$ tahun & $27(20.5)$ \\
$>35$ tahun & \\
Paritas & $55(41.6)$ \\
1 & $74(56.1)$ \\
$2-4$ & $3(2.3)$ \\
$>4$ & \\
Pendidikan & $63(47.7)$ \\
$\leq$ SD & $67(50.8)$ \\
SMP-SMA & $2(1.5)$ \\
$\geq$ S1 & \\
Pekerjaan & $1(0.8)$ \\
Asisten Rumah Tangga & $35(26.5)$ \\
Buruh & $1(0.8)$ \\
Guru & $64(48.5)$ \\
Ibu Rumah Tangga & $14(10.6)$ \\
PNS/Karyawan swasta & $10(7.6)$ \\
Wiraswasta & $7(5.3)$ \\
Wirausaha &
\end{tabular}


Pada Tabel 1 di atas dapat dilihat bahwa sebagian besar subyek yaitu 100 orang (75.8\%) berusia antara 20-35 tahun yang merupakan usia subur, sedangkan dari segi paritas yang terbanyak adalah subyek dengan paritas antara 2-4, yaitu sebanyak 74 orang (56.1\%). Ditinjau dari tingkat pendidikan, hanya $2(1.5 \%)$ subyek yang berpendidikan S1 atau lebih, sebagian terbesar subyek berpendidikan setingkat SD dan SMP-SMA. Mayoritas subyek, yaitu 64 orang (48.5\%) orang tidak bekerja (ibu rumah tangga), dan 35 orang $(26.5 \%)$ bekerja sebagai buruh.

Pada Tabel 2 berikut ini dapat dilihat bahwa terdapat 32 orang $(24.2 \%)$ ibu hamil yang bersuamikan perokok aktif, dan sebanyak 61 orang $(46.2 \%)$ ibu hamil melahirkan bayi dengan berat badan lahir $<2500$ gram (BBLR).

Tabel 2. Distribusi subyek berdasarkan kebiasaan suami merokok dan berat lahir bayi $(n=132)$

\begin{tabular}{lr}
\hline \multicolumn{1}{c}{ Karakteristik Klinik } & n (\%) \\
\hline Suami perokok aktif & $32(24.2)$ \\
Ya & $100(75.8)$ \\
Tidak & \\
Berat lahir bayi & $61(46.2)$ \\
$<2500$ gram & $71(53.8)$ \\
$>2500$ gram & \\
\hline
\end{tabular}

Pada Tabel 3 di bawah ini dapat dilihat bahwa pada kelompok subyek ibu hamil bersuamikan perokok aktif $(\mathrm{n}=32)$ didapatkan kejadian BBLR sebanyak 23 orang $(71.8 \%)$, yang berarti lebih tinggi dibandingkan pada kelompok subyek ibu hamil yang suaminya tidak merokok $(n=100)$ yaitu sebanyak 38 orang $(38 \%)$.

Pada analisis chi square didapatkan nilai $\mathrm{p}=0.000$, yaitu lebih rendah dari batas kemaknaan 0.05, sehingga dapat diartikan bahwa terdapat hubungan yang bermakna antara ibu hamil yang bersuamikan perokok aktif dengan kejadian BBLR.

Pada Tabel 4, kelompok ibu hamil yang suaminya perokok aktif subkelompok subyek yang mengkonsumsi rokok 10 batang atau lebih setiap harinya, proporsi kejadian BBLR lebih tinggi dibandingkan dengan subkelompok yang mengkonsumsi rokok kurang dari 10 batang per hari, demikian juga proporsi kejadian BBLR 9x lebih tinggi dibandingkan non-BBLR.

Ditinjau dari masalah umur ibu hamil, proporsi kejadian BBLR terbanyak didapatkan pada subkelompok usia ibu 2035 tahun, dibandingkan dengan subkelompok usia $\mathrm{ibu}<20$ tahun dan $\geq 35$ tahun. Proporsi kejadian BBLR ternyata paling banyak didapatkan pada subkelompok dengan paritas 2-4, dibandingkan dengan primipara dan grande-multipara.

\section{PEMBAHASAN}

\section{Karakteristik subyek}

Sebagian besar (75.8\%) ibu hamil yang menjadi subyek penelitian mempunyai karakteristik berusia 20-35 tahun yang merupakan kelompok usia subur; dan sebanyak $20.5 \%$ berusia lebih dari 35 tahun yang merupakan salah satu faktor risiko kejadian BBLR. Pada penelitian ini didapatkan sebanyak 3 orang $(2.3 \%)$ ibu hamil dengan paritas lebih dari 4, yang merupakan juga faktor risiko kejadian BBLR. Latar belakang pendidikan sebagian besar subyek yang hanya mencapai tingkat SD, SMP dan SMA (98.5\%) kemungkinan juga berperan pada tingginya angka kejadian BBLR pada penelitian ini, yaitu terkait dengan pengetahuan subyek dalam masalah pencegahan terjadinya BBLR. Pada penelitian ini didapatkan pula bahwa sebagian besar (75.8\%) ibu hamil yang menjadi subyek penelitian ternyata suaminya bukan perokok aktif, berbeda dengan hasil penelitian lain yang menunjukkan prevalensi perokok aktif laki-laki di Indonesia adalah

Tabel 3. Hubungan antara kebiasaan suami merokok dan kejadian BBLR ( $\mathrm{n}=132)$

\begin{tabular}{lcccc}
\hline $\begin{array}{l}\text { Kebiasaan } \\
\text { merokok }\end{array}$ & BBLR & Tidak BBLR & Total & p \\
\hline Ya & n (\%) & n (\%) & n (\%) & $0.000^{*}$ \\
Tidak & $23(71.8)$ & $9(28.2)$ & $32(100)$ & $100(100)$ \\
\hline
\end{tabular}

$* \mathrm{p}<0.05$ berbeda bermakna (chi square) 
Tabel 4. Distribusi subyek ibu hamil yang suaminya perokok aktif berdasarkan banyaknya konsumsi rokok (per hari), paritas, usia dan kejadian BBLR $(n=32)$

\begin{tabular}{|c|c|c|c|}
\hline & $\begin{array}{l}\text { BBLR } \\
\text { n (\%) }\end{array}$ & $\begin{array}{c}\text { Tidak BBLR } \\
\text { n (\%) }\end{array}$ & $\begin{array}{l}\text { Total } \\
\text { n (\%) }\end{array}$ \\
\hline $\begin{array}{l}\text { Konsumsi rokok } \\
<10 \text { batang } \\
\geq 10 \text { batang }\end{array}$ & $\begin{array}{r}5(15.6) \\
18(56.2)\end{array}$ & $\begin{array}{l}7(21.9) \\
2(6.3)\end{array}$ & $\begin{array}{ll}12 & (37.5) \\
20 & (62.5)\end{array}$ \\
\hline $\begin{array}{l}\text { Usia } \\
<20 \text { tahun } \\
20-35 \text { tahun } \\
\geq 35 \quad \text { tahun }\end{array}$ & $\begin{array}{rr}2 & (6.2) \\
17 & (53.1) \\
5 & (15.7)\end{array}$ & $\begin{array}{l}0(0) \\
7(21.9) \\
1(3.1)\end{array}$ & $\begin{aligned} 2 & (6.2) \\
24 & (75.0) \\
6 & (18.8)\end{aligned}$ \\
\hline $\begin{array}{l}\text { Paritas } \\
1 \\
2-4 \\
\geq 4\end{array}$ & $\begin{array}{c}10(31.2) \\
12(37.5) \\
1(3.1)\end{array}$ & $\begin{array}{l}3(9.4) \\
5(15.7) \\
1(3.1)\end{array}$ & $\begin{aligned} 13 & (40.6) \\
17 & (53.2) \\
2 & (6.2)\end{aligned}$ \\
\hline
\end{tabular}

sebesar $66 \%$ dan perempuan sebesar $31.8 \%$; tetapi angka kejadian BBLR pada penelitian ini cukup tinggi yaitu mencapai $46.2 \%$ dari seluruh bayi yang dilahirkan oleh ibu hamil dilibatkan sebagai subyek pada penelitian ini. Prevalensi BBLR di seluruh dunia diperkirakan $15 \%$ dari seluruh kelahiran, dan lebih dari $97 \%$ di antaranya terjadi di negara berkembang atau sosial ekonomi rendah. (1) Sedangkan World Health Organization (WHO) melaporkan angka kejadian BBLR di Indonesia sebesar 9\%. ${ }^{(2)}$

Perbedaan angka kejadian BBLR ini kemungkinan terjadi karena ada perbedaan dalam hal cara pengumpulan data di lapangan dan di rumah sakit

Hubungan antara paparan rokok pada ibu hamil yang bersuamikan perokok aktif dan kejadian BBLR

Dari hasil analisis data penelitian ini didapatkan hubungan yang bermakna antara ibu hamil yang bersuamikan perokok aktif dan kejadian BBLR dengan nilai $\mathrm{p}=0.000$ $(\mathrm{p}<0.05)$. Penelitian ini hasilnya sejalan dengan penelitian dari Lestari KSD et al. tentang Paparan Asap Rokok pada Ibu Hamil di Rumah Tangga terhadap Risiko Peningkatan Kejadian Bayi Berat Lahir Rendah di Kabupaten Gianyar pada tahun 2013 dengan p-value sebesar 0.001.(9) Demikian pula hal ini selaras dengan hasil penelitian dari Wahyuningsih CS et al. tentang Hubungan Paparan Asap Rokok dalam Rumah dan Usia Ibu Bersalin dengan Berat Bayi Lahir di RSUD Wonosari Kabupaten Gunung Kidul pada tahun 2016 dengan p-value sebesar $0.007 .^{(10)}$ Hal ini sesuai dengan penelitian yang dilakukan oleh Nurlalila Ramadhan mengenai Hubungan Ibu Hamil Perokok Pasif Dengan Kejadian Bayi Berat Lahir Rendah di Badan Layanan Umum Daerah RSU Meuraksa-Banda Aceh, yang didapatkan bahwa ibu hamil yang terpapar asap rokok dari suami perokok aktif selama kehamilannya akan berisiko 5.80 kali lebih tinggi untuk melahirkan BBLR dibandingkan dengan ibu hamil yang tidak terpapar dengan asap rokok selama kehamilannya. ${ }^{(1)}$ Selain itu penelitian ini pun sejalan dengan penelitian yang dilakukan oleh Isroiani A et al. ${ }^{(11)}$ mengenai Hubungan Suami Perokok dengan Terjadinya Bayi Berat Badan Lahir Rendah di RSUD Sidoarjo, yang menyatakan bahwa terdapat hubungan suami perokok dengan terjadinya BBLR di RSUD Sidoarjo. Namun hasil penelitian ini bertentangan dengan hasil penelitian dari Mahdalena et al. ${ }^{(12)}$ mengenai Pengaruh Rokok Terhadap Berat Badan Bayi Baru Lahir di RSUD Banjarbaru, yang berdasarkan analisis bivariat dengan uji Kruskal-Wallis didapatkan nilai signifikansi 0.78 , nilai tersebut lebih besar dari nilai $\alpha$ (0.05), sehingga disimpulkan bahwa tidak ada pengaruh rokok terhadap berat badan lahir dari ibu hamil. Perbedaan hasil ini disebabkan karena adanya perbedaan metode penelitian yang dilakukan, yaitu dalam penentuan kriteria inklusi yang melibatkan perokok pasif dan perokok aktif, serta cara pengambilan sampel yang dilakukan secara purposive sampling. 
Hasil penelitian ini juga menunjukkan bahwa persentase kejadian BBLR lebih tinggi didapatkan pada kelompok ibu hamil yang suaminya merokok 10 batang atau lebih per hari $(56.2 \%)$ dibandingkan dengan yang kurang dari 10 batang rokok per hari (15.6\%). Hasil tersebut sesuai dengan hasil penelitian yang dilakukan oleh Ridwan yang menunjukkan bahwa angka kejadian BBLR dari ibu hamil yang suaminya perokok lebih dari 10 batang per hari sebesar $59.5 \%$ dan untuk yang kurang dari 10 batang sebanyak $45.5 \%$, dengan odds ratio (OR) sebesar 1.76 (95\% CI: 0.795-3.897), yang berarti ibu hamil yang bersuamikan perokok lebih dari 10 batang per hari berisiko 1.76 kali lebih besar melahirkan BBLR. ${ }^{(3,13-15)}$ Hasil penelitian Irnawati menggambarkan ibu hamil perokok pasif yang terpapar asap rokok 1-10 batang perhari berisiko 2.4 kali lebih sering untuk terjadinya bayi berat lahir rendah (BBLR) dengan $\mathrm{OR}=2.42 ; 95 \% \mathrm{CI}$ 1.24-4.71. Ibu hamil yang terpapar asap rokok $\geq 11$ batang perhari berisiko 3.1 kali lebih sering mengalami BBLR dibanding ibu yang tidak terpapar (OR=3.1; 95\% CI 1.50-6.70).

Pada kelompok ibu hamil bersuamikan perokok aktif yang dilibatkan sebagai subyek penelitian, ditinjau dari aspek umur ibu hamil, proporsi kejadian BBLR pada subkelompok yang berusia $>35$ tahun lebih besar dibandingkan dengan subkelompok yang berusia $<20$ tahun maupun antara 20-35 tahun. Hal ini menunjukkan bahwa selain kemungkinan karena faktor suami ibu hamil yang aktif merokok, usia ibu ketika hamil juga berperanan sebagai faktor yang berhubungan dengan kejadian BBLR. ${ }^{(14-16)}$

Pada kelompok subyek ibu hamil yang bersuamikan perokok aktif, kejadian BBLR didapatkan paling banyak pada subkelompok ibu hamil grandemultipara (paritas $>4$ ), sedangkan pada subkelompok paritas 1 (primipara) dan paritas 2-4 (multipara), didapatkan persentase kejadian BBLR yang hampir sama banyak. Pada subkelompok primipara didapatkan kejadian BBLR lebih banyak dibandingkan dengan yang tidak BBLR; demikian juga pada kelompok multipara lebih banyak didapatkan bayi BBLR daripada yang tidak BBLR. Hasil penelitian di atas juga menunjukkan bahwa kejadian BBLR cenderung meningkat atau lebih tinggi seiring dengan meningkatnya paritas ibu hamil. ${ }^{(17-18)}$

Keterbatasan penelitian ini adalah bahwa desain potong-lintang (cross-sectional) yang dipilih tidak dapat menunjukkan hubungan sebab-akibat antara paparan asap rokok terhadap ibu hamil dengan kejadian BBLR, yang mana untuk itu dibutuhkan penelitian longitudinal dengan melakukan kontrol terhadap faktor-faktor lain yang dapat mengakibatkan BBLR di luar pengaruh asap rokok.

\section{KESIMPULAN}

Dari hasil penelitian ini dapat disimpulkan bahwa terdapat hubungan antara ibu hamil yang bersuamikan perokok aktif dengan kejadian bayi berat lahir rendah (BBLR).

\section{UCAPAN TERIMA KASIH}

Penulis mengucapkan banyak terima kasih kepada Pimpinan beserta seluruh staf medis dan non medis RSUD Karawang yang telah memberi ijin, demikian juga kepada para subyek penelitian yang telah bersedia dan bersikap sangat membantu dalam pelaksanaan penelitian ini.

\section{KONFLIK KEPENTINGAN}

Penulis menyatakan bahwa tidak ada konflik kepentingan dalam pelaksanaan penelitian ini.

\section{KONTRIBUSI KEPENGARANGAN}

GSP menyusun konsep dan rancangan penelitian, pengumpulan data, analisis data, interpretasi data dan menyiapkan makalah. RW membantu menyusun rancangan penelitian, analisis dan interpretasi data, serta revisi makalah akhir untuk publikasi.

\section{DAFTAR REFERENSI}

1. Ramadhan N. Hubungan Antara Ibu Hamil Perokok Pasif dengan Kejadian Bayi Berat Lahir Rendah di Badan Layanan Umum Daerah RSU Meuraksa Banda Aceh. Jurnal Ilmiah STIKES U'Budiyah. 2012;1(2):27-33 
2. The United Nation Children's Fund, World Health Organization. Low Birth-weight: Country, Regional and Global Estimates. 2004. [cited 2017 May 22]. Available from: http:// www.who.int/reproductivehealth/publications/ monitoring/9280638327/en/

3. Irnawati, Hakimi M, Wibowo T. Ibu Hamil Perokok Pasif sebagai Faktor Risiko Bayi Berat Lahir Rendah. Jurnal Klinik Gizi Indonesia. 2011;8:54-9.

4. Hanum H, Wibowo A. Pengaruh Paparan Asap Rokok Lingkungan pada Ibu Hamil terhadap Kejadian Berat Bayi Lahir Rendah. Majority. 2016;5(5):22-6

5. Bada HS, Das A, Bauer CR, Shankaran S, Lester BM, Gard CC, et al. Low Birth Weight and Preterm Births: Etiologic Fraction Attributable to Prenatal Drug Exposure: Low Birth Weight and Preterm Births. Journal of Perinatology. 2005;25:631-7.

6. Badan Penelitian dan Pengembangan Kesehatan Kementrian Kesehatan RI. Riset Kesehatan Dasar 2013. Jakarta: Kemenkes RI; 2013. Available from: http://www.depkes.go.id/resources/download/ general/Hasil\%20Riskesdas\%202013.pdf

7. Mackay J, Ritthiphakdee B, Reddy KS. Tobacco Control in Asia. Lancet. 2013; 381(9877):15817.DOI:https://doi.org/10.1016/S01406736(13)60854-5

8. Reardon JZ. Environmental Tobacco Smoke: Respiratory and Other Health Effects. Clin Chest Med. 2007;28(3):559-73. DOI: 10.1016/j. ccm.2007.06.006

9. Lestari KSD, Putra IWGAE, Karmaya M. Paparan Asap Rokok pada Ibu Hamil di Rumah Tangga Terhadap Risiko Peningkatan Kejadian Berat Bayi Lahir Rendah di Kabupaten Gianyar. Public Health and Preventive Medicine Archieve. 2015; 3(1):139

10. Wahyuningsih CS, Trisnowati H, Fitriani A. Hubungan Paparan Asap Rokok dalam Rumah dan Usia Ibu Bersalin dengan Berat Bayi Lahir di RSUD Wonosari Kabupaten Gunungkidul. Jurnal Formil (Forum Ilmiah) Kes Mas Respati. 2016; 1(2):121-129

11. Isroaini A, Saidah N. Hubungan Suami Perokok dengan Terjadinya Bayi Berat Badan Lahir Rendah di RSUD Sidoarjo. Hospital Majapahit. 2012; 4(2):81-101

12. Mahdalena, Ningsih ESP , Noor S. Pengaruh Rokok Terhadap Berat Badan Bayi Baru Lahir di RSUD Banjarbaru. Jurnal Skala Kesehatan. 2014;5(2):1-6. DOI: https://doi.org/10.31964/jsk. v5i2.23

13. Proverawati A, Ismawati C. Berat Badan Lahir Rendah (BBLR). Yogyakarta: Nuha Medika; 2010.

14. Pramono MS, Putro G. Risiko Terjadinya Berat Bayi Lahir Rendah Menurut Determinan Sosial, Ekonomi, dan Demografi di Indonesia. Buletin Penelitian Sistem Kesehatan. 2009;12(2):127-32.

15. Astuti S, Susanti AI, Elista R. Gambaran Paparan Asap Rokok pada Ibu Hamil Berdasarkan Usia Kehamilan di Desa Cintamulya Kecamatan Jatinangor Kabupaten Sumedang. Jurnal Sistem Kesehatan. 2016;2(1):22-7. DOI: https://doi. org/10.24198/jsk.v2i1.10413

16. Nur R, Arifuddin A, Novilia R. Analisis Faktor Risiko Kejadian Berat Badan Lahir Rendah di Rumah Sakit Umum Anutapura Palu. Jurnal Preventif. 2016;7(1):29-42.
17. Susilowati E, Wilar R, Salendu P. Faktor Risiko yang Berhubungan dengan Kejadian Berat Badan Lahir Rendah pada Neonatus yang Dirawat di RSUP Prof. Dr. R. D. Kandou. Jurnal e-Clinic (eCL). 2016;4(2):1-7

18. Mahayana SAS, Chundrayetti E, Yulistini. Faktor Risiko yang Berpengaruh terhadap Kejadian Berat Badan Lahir Rendah di RSUP Dr. M. Djamil Padang. Jurnal Kesehatan Andalas. 2015;4(3):66473 